\title{
Sentidos formativo e didático das tecnologias digitais
}

\author{
Rosária Helena Ruiz Nakashima' \\ Elzimar Pereira Nascimento Ferraz ${ }^{2}$
}

Resumo

O texto apresenta o processo de revisão e reconstrução da disciplina de Didática das licenciaturas em História e em Matemática, na Universidade Federal do Tocantins, integrada à cultura digital, suas possibilidades de interação e produção de conhecimentos. Nesta reflexão pedagógica, buscou-se integrar recursos como Prezi, Wordpress, Moodle e vídeos, nas atividades curriculares, compreendendo sua intencionalidade para a formação político-pedagógica do futuro professor. Nesta pesquisa qualitativa, vinte e um (21) acadêmicos avaliaram o sentido formativo do uso das Tecnologias Digitais de Informação e Comunicação (TDIC) na educação e as respostas foram compreendidas a partir das categorias de análise: especificidade da Didática Geral; reconstrução do conteúdo da Didática e articulação do pensar sobre a metodologia de ensino na Didática e na Didática "vivida" (CANDAU, 1996). As respostas dos acadêmicos revelaram a importância do trabalho de mídia-educação, como um tema transversal na formação inicial de professores como "condição de pertencimento e de cidadania instrumental e cultural" (FANTIN, 2012) na atualidade.

Palavras-chave: Didática. Mídia-educação. Formação docente.

\footnotetext{
1 Doutora em Educação (Universidade de São Paulo). Mestre em Educação (Universidade Estadual de Campinas). Pedagoga. Professora Adjunta do Curso de Licenciatura em História na Universidade Federal do Tocantins (Câmpus de Araguaína). E-mail rosaria@uft.edu.br. 2 Doutora em Educação (Universidade Federal de Goiás). Mestre em Educação (Universidade Católica de Brasília). Pedagoga. Professora Adjunta do Curso de Licenciatura em Matemática na Universidade Federal do Tocantins (Câmpus de Araguaína). E-mail: elzimar@uft.edu.br.
} 


\section{Formative meaning and didactic of digital technologies}

\section{Sentido de formación y didáctico de tecnologías digitales}

Abstract

The text presents the process of the review process and reconstruction of Teaching discipline of degrees in history and mathematics at the Federal University of Tocantins, integrated digital culture and its possibilities of interaction and knowledge production. This pedagogical reflection sought to integrate features such as Prezi, Wordpress, Moodle and videos, in curricular activities, including its intention to political and pedagogical training of future teachers. In this qualitative research, twenty-one (21) students evaluated the formative sense of the use of Digital Information and Communication Technology (DICT) in education and the answers were understood from the analysis categories: specificity of the general didactic; reconstruction of the contents of the didactic and articulation thinking about teaching methodology in didactic and teaching "lived" (CANDAU, 1996). Responses from academic revealed the importance of media education work, as a cross-cutting theme in the initial training of teachers as "belonging condition and instrumental and cultural citizenship" (FANTIN, 2012) today.

Keywords: Teaching. Media education. Teacher training.

\section{Resumen}

El texto presenta el proceso de revisión y reconstrucción de la disciplina didáctica de grados de la historia y matemáticas en la Universidad Federal de Tocantins, la cultura digital integrado y sus posibilidades de interacción y producción de conocimientos. Esta reflexión pedagógica buscó integrar características como Prezi, Wordpress, Moodle y vídeos, en las actividades curriculares, incluyendo su intención de formación política y pedagógica de los futuros docentes. En esta investigación cualitativa, de veintiún (21) estudiantes evaluaron el sentido formativo de la utilización de Tecnologías Digitales de la Información y Comunicación (TDIC) en la educación y las respuestas se entiende a partir de las categorías de análisis: la especificidad de la didáctica general; reconstrucción de los contenidos del pensamiento didáctico y conjunta sobre la enseñanza de la didáctica y didáctica "vivió" (CANDAU, 1996). Las respuestas de académicos revelaron la importancia del trabajo de educación para los medios, como un tema transversal en la formación inicial de los docentes como "condición pertenencia y ciudadanía instrumental y cultural" (FANTIN, 2012) hoy.

Palabras clave: Enseñanza. La educación en medios. La formación del profesorado. 


\section{Introdução}

As Diretrizes Curriculares Nacionais para Formação de Professores da Educação Básica (BRASIL, 2002b) apresentam princípios, fundamentos e procedimentos que objetivam nortear os currículos dos cursos de graduação. Em seu artigo $2^{\circ}$, o documento destaca orientações à formação para a atividade docente, sendo que nesta produção textual foram enfatizadas três delas, isto é, o preparo para o ensino visando à aprendizagem do estudante; o uso de tecnologias da informação e comunicação (TIC), metodologias, estratégias e materiais de apoio inovadores; e o desenvolvimento de hábitos de colaboração e de trabalho em equipe.

Considerou-se que tais orientações contribuíram para encadear um processo de revisão e reconstrução da disciplina Didática, dos cursos de licenciatura em História e em Matemática, na Universidade Federal do Tocantins, Câmpus de Araguaína. Em outras palavras, colaboraram para a promoção de atividades favoráveis ao desenvolvimento de trocas de experiências, de habilidades para saber ouvir, opinar, dialogar, elucidar problemas e propor soluções.

Nesta investigação, partiu-se do problema de como superar a visão instrumental da Didática, concebendo o processo de ensino como"prática social concreta" (VEIGA, 2005). A partir de uma pesquisa-ação (BARBIER, 2002), apoiada por tecnologias digitais de informação e de comunicação (TDIC), envolveu vinte e um (21) acadêmicos, nove (09) de História e doze (12) de Matemática, que avaliaram o sentido formativo do uso das tecnologias na educação. De acordo com Fantin (2012, p. 437), “em um momento em que se discute a presença e difusão cada vez maior das tecnologias da informação e comunicação na escola, a formação de professores não pode deixar de refletir sobre as possibilidades de mediação educativa que isso implica". Assim, no decorrer do semestre, novas abordagens didático-pedagógicas foram contempladas na formação inicial das respectivas licenciaturas.

No desenvolvimento da disciplina Didática buscou-se compreender as relações e inter-relações constituin- tes do processo da formação de professores e a prática educativa no ensino de Histórica e de Matemática, numa perspectiva diferente da tendência tradicional. Fez-se necessário utilizar práticas pedagógicas alternativas para promover a formação de profissionais, voltada para o desenvolvimento de metodologias fundamentadas em paradigmas mais condizentes com a realidade escolar atual. Este artigo foi organizado em dois diferentes momentos articulados, apresentando os principais aspectos teóricos e práticos inerentes ao desenvolvimento da pesquisa em Didática.

\section{Contexto da pesquisa}

As professoras, responsáveis pela disciplina nas licenciaturas em História e Matemática, compartilhavam da crença de que era necessário superar a visão da didática instrumental, em busca do "fundamental da didática" (CANDAU, 2011, p. 71). Ao mesmo tempo, depararam-se com a necessidade de abordar na disciplina questões de caráter técnico da Didática. Diante desse desafio, no primeiro semestre de 2014, ambas se reuniram durante o planejamento, desenvolvimento e avaliação da disciplina para repensar a Didática na formação de futuros professores da educação básica, considerando que, no projeto pedagógico dos dois cursos, a Didática se configura como disciplina de um semestre, com carga horária de 60 horas.

No período de planejamento foram elaborados os procedimentos utilizados no decorrer do semestre para desenvolver a proposta de uma pesquisa-ação, fundamentada em Barbier (2002), que consistiu na identificação do problema a ser investigado; planejamento e realização do processo de pesquisa em espiral (situação-problema -> planejamento -> ação -> observação -> reflexão -> novo planejamento da experiência pedagógica); seleção de técnicas de pesquisa e, complementarmente, a teorização, a avaliação e a divulgação dos resultados alcançados.

Em uma pesquisa-ação "não se trabalha sobre os outros, mas e sempre com os outros" (BARBIER, 2002, p.14), reconhecendo que a gênese do problema pertence a um grupo, a um contexto específico. Portanto, com o intuito 
de elencar possíveis problemáticas no processo de construção de conhecimentos didáticos, na primeira aula, foram levantadas as demandas dos estudantes, a saber: como elaborar planos de ensino e de aula, utilizar o quadro negro, o projetor multimídia (como ligá-lo e utilizá-lo pedagogicamente), o laboratório de informática, bem como estudar estratégias para desmistificar o ensino de Matemática e de História e outras habilidades técnicas que os estudantes consideraram importantes para serem exercitadas durante a disciplina.

Os discentes também apresentaram seus receios em relação à futura profissão, principalmente no contexto das escolas públicas, tais como: indisciplina de alunos nas aulas; desvalorização profissional; tempo insuficiente para o professor planejar; quantidade elevada de alunos por turma; infraestrutura precária nas escolas; número insuficiente de professores concursados e rotatividade de professores contratados, provocando a sobrecarga de alguns, além de outros desafios sociais, culturais, afetivos e morais elencados como preocupações do magistério na educação básica.

Diante dessas demandas, e como parte do processo de pesquisa, iniciou-se um exercício de reflexão em torno da prática pedagógica e dos modos de inovar que caracterizam a ação docente, considerando que "a concepção de Didática se amplia com as observações em sala de aula, espaço, em que se explicita o modo de pensar e construir o conhecimento nesse campo de estudo." (VEIGA et al., 2009, p. 5).

Com o objetivo de apresentar exemplos práticos da dimensão técnica da Didática, no início de todas as aulas foram registradas as pautas das aulas, contendo as ações planejadas, articuladas com as demandas dos estudantes e da ementa dos cursos, a saber: os fundamentos e a ação docente nas diferentes tendências pedagógicas, a didática como atividade integradora na construção de propostas globalizadas, sob diferentes modalidades de operacionalização: sistemas de projetos, unidades de experiência, centros de interesses; professor numa perspectiva de profissionalização; papel da investigação no processo de formação docente.
Durante o semestre foram trabalhados os livros "Pedagogia da Autonomia", de Paulo Freire, com apresentação de cada capítulo pelos estudantes e, na sequência, discussão sobre a prática; "Educação matemática: da teoria à prática", de Ubiratan D'ambrósio; "História na sala de aula", de Leandro Karnal, bem como os Parâmetros Curriculares Nacionais (PCN), relacionando as leituras com os receios discentes em relação à profissão e a importância dos saberes docentes, visando a aprendizagem dos estudantes (BRASIL, 2002b).

Também foi realizado um estudo do meio, com o objetivo de conhecer os procedimentos pedagógicos, pela aula-campo, na Escola Família Agrícola (EFA) de Colinas-TO, comumente conhecida como EFA "Zé de Deus". A principal característica dessa escola é a pedagogia da alternância, uma proposta educacional diferenciada aos filhos de pequenos agricultores que possibilita a permanência do aluno na escola, em consonância com o meio no qual vive. A aprendizagem, mesmo com limitações para desenvolver conteúdos oficiais, é sustentada pela relação entre educação formal e informal, no sentido de valorizar aspectos culturais dos camponeses. Consequentemente, o ensino contextualizado engendra maior capacidade para enfrentar novas situações da vida escolar, familiar e comunitária, promovendo a interlocução com a realidade camponesa.

Para desenvolver hábitos de colaboração e de trabalho em equipe (BRASIL, 2002b), foi realizado um "painel integrado" para discussão do texto de Candau (2011), “Da Didática Fundamental ao Fundamental da Didática", aliada à compreensão de quatro pressupostos (VEIGA, 2005) que caracterizam a Didática como área de estudo: a) educação como um processo construtivo e permanente de emancipação humana; b) compromisso com a qualidade e democratização da escola pública; c) professor, como agente social, que procura colocar em questão a lógica modernizadora e d) metodologia de pesquisa como modo de apropriação ativa de conhecimento.

$\mathrm{O}$ uso de TDIC, de metodologias, estratégias e materiais de apoio inovadores (BRASIL, 2002b) foi integrado à disciplina a partir do entendimento de que os objetos técnicos não são "mágicos" a fim de garantir qualidade na 
educação. "É como se as TIC fossem dotadas de poder miraculoso! Nessa perspectiva, deixam de ser entendidas como produções histórico-sociais" (MOREIRA; KRAMER, 2007, p. 1042). Portanto,

[...] criar condições para o desenvolvimento de uma competência midiática na formação envolve a discussão sobre apreciação, recepção e produção responsável no sentido de uma mediação sistemática que contribua com uma atitude mais crítica em relação aos modos de ver, navegar, produzir e interagir com as mídias. Afinal, a experiência com a cultura digital está construindo não apenas novos usos da linguagem, mas novas formas de interação a serem problematizadas no currículo escolar. (FANTIN, 2012, p. 438).

A partir dessa necessidade de problematização, foi realizada uma reflexão com os acadêmicos, destacando que o uso das TDIC pressupõe mudanças metodológicas dos conteúdos tradicionalmente ensinados nas salas de aula. Ao compreender a intencionalidade do uso das TDIC, para a formação político-pedagógica do futuro professor, foram planejadas atividades colaborativas, envolvendo a exploração do recurso Prezi' para estudo das tendências pedagógicas (LIBÂNEO, 1986); o uso de vídeos para ilustrar e complementar o entendimento de conteúdos; a criação de blogs (WordPress) e o uso do ambiente virtual de aprendizagem o Moodle, como espaços para reflexão sobre os pressupostos da Didática (VEIGA 2005) e a elaboração dos planos de ensino e de aula, apoiada por editor de texto.

\section{Revisão e reconstrução da disciplina de didática: a avaliação dos acadêmicos}

Em uma perspectiva qualitativa, a pesquisa-ação priorizou a investigação do processo de revisão e reconstrução da disciplina de Didática, dos cursos de licenciatura em História e em Matemática, atentando-se para a preservação do seu caráter específico. Portanto, este estudo foi permeado pela necessidade de se pensar como articular ações metodológicas, uso pedagógico das TDIC e materiais de apoio inovadores (BRASIL, 2002b), em busca da superação da visão instrumental da Didática, concebendo o ensino como "prática social concreta" (VEIGA, 2005).

Para responder a essa problematização, foram realizadas reuniões das professoras envolvidas neste estudo para planejamentos didáticos e avaliação do desenvolvimento das aulas, além de observação participante, por meio de contato direto e prolongado das pesquisadoras com a situação investigada. Vinte e um (21) acadêmicos foram avaliando o sentido formativo das TDIC durante todo o semestre, nos momentos de negociação da pauta das aulas e das propostas de atividades a serem desenvolvidas, de seleção das tecnologias a serem utilizadas e dos feedbacks realizados no decorrer da disciplina.

Para sistematizar esse processo de avaliação, eles responderam um questionário com cinco questões abertas. As respostas foram analisadas a partir triangulação dos dados coletados nas observações diretas e indiretas, reuniões de planejamento, feedback dos estudantes e fundamentos teóricos, com base nas categorias de análise de Candau (1996): especificidade da Didática Geral; reconstrução do conteúdo da Didática e articulação do pensar sobre a metodologia de ensino na Didática e a Didática "vivida".

Também foi proposto aos acadêmicos a realização de uma autoavaliação, composta de oito (08) questões, na qual puderam fazer o exercício de avaliar o próprio desempenho na disciplina. Ao serem convidados a atribuírem uma nota (1 a 10) para si mesmos, refletiram sobre questões importantes da ação docente, tais como: pontualidade, interesse, dedicação, comunicação, participação, organização, respeito, cooperação e domínio de conteúdo.

Esta pesquisa-ação permitiu investigar a relação teoria e prática; envolver os diferentes sujeitos do processo educativo; engendrar reflexões que suscitaram em intervenções na ação pedagógica e desconstruir a visão linear do processo de ensino e aprendizagem, externada inicialmente pelos acadêmicos, conforme análise realizada a seguir. 


\section{Especificidade da Didática Geral}

O termo "Didática" deriva da expressão grega "techné didaktiké", isto é, arte ou técnica de ensinar. Segundo Oliveira (1988, p. 36), "Didactica Magna, obra de Comênio, escrita no século XVII, é considerada o primeiro marco significativo no processo de sistematização da Didática, a partir do qual ela se populariza na literatura pedagógica". Quanto ao papel da Didática na formação de professores Candau (1983, p. 106-107) explica que:

O papel da Didática na formação dos educadores não está, para muitos, adequadamente definido, o que gera indefinição do seu próprio conteúdo. (...) sua especificidade é garantida pela preocupação com compreensão do processo ensino-aprendizagem e a busca de formas de intervenção na prática pedagógica. A Didática tem por objetivo 'como fazer' a prática pedagógica, mas este só tem sentido quando articulado ao 'para que fazer' e ao 'por que fazer'.

Em outras palavras, o papel da Didática nas licenciaturas é criar espaços para a compreensão de que a formação dos professores não pode ser pautada na racionalidade técnica, mas sim no protagonismo do professor e do estudante no desenvolvimento do processo educativo. Nesse sentido, os sujeitos da pesquisa ${ }^{2}$ reconheceram a relevância do saber docente relativo à compreensão do processo de ensino e de aprendizagem, como mostram os excertos a seguir:

A3: Eu achava que a disciplina de Didática era para aprender só como ensinar. Mas percebi que é muito mais, porque envolve entender o processo educativo como um todo, tanto a formação do professor para ensinar, como os processos de construção do conhecimento pelos alunos.

A13: Aprendi que para trabalhar na educação nos dias atuais requer uma postura diferente do que era acostumando no passado, devido as novas tecnologias e o avanço da sociedade. $\mathrm{O}$ educador deve estar sempre atualizado e preparado para enfrentar os diversos problemas encontrados no seu dia-a-dia.
Candau $(1983,2011)$ ressalta a transposição de uma didática instrumental para uma didática fundamental que articulasse as dimensões política, técnica e humana na prática pedagógica. Os acadêmicos apontaram para a compreensão de que a Didática deve se preocupar com o "como fazer", articulado com "para que" e "por que" fazer, conforme destacado nos excertos abaixo:

\begin{abstract}
A1: As aulas sobre a elaboração de planos de ensino e de aula foram muito importantes, pois ficou clara a prática do planejamento como essencial para o processo de ensino e de aprendizagem. Além disso, como vimos no texto da Candau, sobre o fundamental da Didática, o processo de planejar deve ser acompanhado da reflexão político-social sobre a intencionalidade do ensino do conteúdo.
\end{abstract}

A4: Os meios tecnológicos estão cada vez mais presente no cotidiano escolar, e na maioria das vezes os professores não são preparados para tirar proveito deles. Acredito que eu estou mais familiarizado depois do contato com eles, sabendo como utilizá-los na educação, sempre tendo em mente como ele será útil para o ensino dos conteúdos, inclusão digital dos alunos e não usar apenas porque está na "moda".

A visão dos sujeitos da pesquisa apontou para a importância da formação do professor articulado ao "trabalho de mídia-educação, entendida como a possibilidade de educar para/sobre as mídias, com as mídias e através das mídias, a partir de uma abordagem crítica, instrumental e expressivo-produtiva" (FANTIN, 2012, p. 438), compreendendo a intencionalidade das TDIC para a formação político-pedagógica do futuro professor.

Na disciplina, buscou-se estabelecer inter-relações escolares constituintes do processo de formação do professores na área das tecnologias digitais, que só tendem a avançar. Entretanto, em seus feedbacks sobre o desenvolvimento da disciplina de Didática, os acadêmicos apontaram a dificuldade de acesso à internet em algumas escolas públicas, inviabilizando, por exemplo o uso do Prezi e do blog, bem como a falta de gestão democrática para apoiar as inovações metodológicas. 
Freire (1996) traz uma reflexão pertinente sobre o papel da tecnologia na educação, consciente das transformações que a informática submeteu às práticas sociais. Além disso, declara o quanto as tecnologias digitais vieram para ficar e transformar as práticas pedagógicas.

Nunca fui ingênuo apreciador da tecnologia: não a divinizo, de um lado, nem a diabolizo, de outro. Por isso mesmo sempre estive em paz para lidar com ela. Não tenho dúvida nenhuma do enorme potencial de estímulos e desafios à curiosidade que a tecnologia põe a serviço das crianças e dos adolescentes das classes sociais chamadas favorecidas. Não foi por outra razão que, enquanto secretário de educação da cidade de São Paulo, fiz chegar à rede das escolas municipais o computador. Ninguém melhor do que meus netos e minhas netas para me falar de sua curiosidade instigada pelos computadores com os quais convivem. (FREIRE, 1996, p. 97-98).

$\mathrm{Na}$ atualidade, a especificidade da Didática deve prever a integração das TDIC para contribuir com o processo de problematização dos conteúdos específicos das disciplinas, tendo em vista as modificações nas "concepções de escola e nas formas de construção do saber, resultando na necessidade de se repensar a intervenção pedagógico-didática na prática escolar (LIBÂNEO; PIMENTA, 2002, p. 38). Esses aspectos também são reconhecidos nos excertos abaixo:

A2: Como futuros professores de jovens necessitamos estar por dentro das inovações e de recursos metodológicos-tecnológicos que auxiliem no nosso trabalho. Os trabalhos nos laboratórios de informática nos ajudaram a perceber como as tecnologias podem auxiliar no ensino de História, pois vimos o quanto os alunos podem criar conhecimentos com elas.

A8: Percebi o quanto o uso das novas tecnologias podem contribuir com a nossa formação, pois podemos utilizá-las para desenvolver metodologias variadas, auxiliando alunos com diferentes estilos de aprendizagem, visando uma aprendizagem significativa.

A11: O uso do Prezi foi ótimo, uma ferramenta riquíssima que nos possibilitou uma percepção dinâmica dos conteúdos estudados.
Nesse sentido, Veiga (2005) reforça que a globalização e as TDIC vêm provocando reorganizações no trabalho, nas relações sociais, na produção de cultura e na organização do trabalho pedagógico. Portanto, há questionamentos que contribuem para a reflexão sobre tais transformações, apoiadas pelo o avanço científico-tecnológico como: Que professor queremos formar? As TDIC auxiliam no desenvolvimento de habilidade de ordem superior em estudantes? Como as TDIC podem colaborar para a problematização dos conteúdos curriculares?

Para (MOREIRA; KRAMER, 2007, p. 1048), "ao lado da incorporação da tecnologia, cabe questionar o modelo de sociedade que se quer construir" e Fantin (2012, p. 439) aponta que novos desafios estão surgindo na sociedade contemporânea, pois "através da interatividade que estas mídias propiciam, a comunicação acontece entre pessoas e não só com conteúdos, e as pessoas não são apenas destinatárias de informações, mas também produtoras e autoras de conteúdos que compartilham com outros usuários". Tais reflexões fazem parte da formação inicial e continuada dos professores, articulada com os novos desafios apresentados constantemente pela sociedade, que vão exigindo modificações no conteúdo da Didática, exigindo uma abordagem de mídia-educação.

\section{Reconstrução do conteúdo da Didática}

Segundo Candau (1996, p. 18), "a busca de alternativas para o ensino de Didática supõe analisar o conteúdo habitualmente veiculado por esta disciplina e reconstruí-lo a partir da tentativa de compreender a prática pedagógica em suas diferentes dimensões e relações". Nesta investigação, os sujeitos da pesquisa apresentaram suas críticas sobre o que foi veiculado pela disciplina. O fato de conhecer tais críticas foi essencial pois, de acordo com Barbier (2002), um dos objetivos de uma pesquisa-ação é a mudança de discursos e de práticas, ou seja, a avaliação crítica dos estudantes sobre a disciplina de Didática será considerada no processo de planejamento da sua próxima edição.

A3: Uma sugestão para o próximo semestre é diminuir a quantidade de trabalhos que de- 
pendessem da internet, pois muitos não têm o acesso fácil e rápido e nas escolas públicas também é precário.

A6: Gostaria de ter mais aulas no laboratório de informática para trabalhar outras tecnologias que possam ser usadas em sala de aula.

A17: Acrescentaria mais apresentações dos alunos do conteúdo da matéria. Fazer uma comparação da Didática dos professores para saber se estão utilizando qual tendência. Laboratório de informática equipado e com sistema compatível com o Prezi.

A1: Mesmo tendo sido solicitadas um número significativo, acredito que poderíamos ter lido mais textos sobre didática, e feito mais produções escritas durante o semestre, unido as questões técnica, política e social do processo de ensino.

No excerto do $A 1$, observa-se a preocupação apontada por Candau (1983) no que diz respeito à perspectiva fundamental da Didática em assumir a multidimensionalidade do processo de ensino e de aprendizagem, compreendendo que "a prática pedagógica, exatamente por ser política, exige competência técnica" (p. 21). Portanto, as dimensões técnica, humana e política estão articuladas, conforme observou outro acadêmico:

A4: A disciplina me ajudou a perceber que há vários fatores que interferem na educação, tanto as politicas públicas, como a família, a própria comunidade. Percebi que o professor e a gestão da escola é muito importante para gerenciar a formação integral (parte afetiva, intelectual, física, emocional...) do aluno.

Libâneo (1986, p. 52) complementa essa visão ao afirmar que:

A ênfase no saber ser, sem dúvida fundamental para se definir uma postura crítica do educador frente ao conhecimento e aos instrumentos de ação, não pode dissolver as outras duas dimensões da prática docente, o saber e o saber fazer, pois a incompetência no domínio do conteúdo e no uso de recursos de trabalho compromete a imagem do professor-educador. Tornar nossa prática ineficiente põe em risco os próprios fins políticos dessa prática.

Nesse sentido, o processo de reconstrução do conteúdo da Didática requer a explicitação dos seus pressupostos, isto é, do contexto em que as abordagens metodológicas foram geradas, bem como "a visão de homem, de sociedade, de conhecimento e de educação que veiculam" (CANDAU, 1996, p. 16). Nesta pesquisa, buscou-se fundamentar o planejamento e a realização de propostas, pautados na pedagogia crítica. Para Veiga (2005, p. 44),

a didática tem uma importante contribuição a dar: clarificar o papel sociopolítico da educação, da escola e, mais especificamente, do ensino. Assim, o enfoque a didática, de acordo com os pressupostos de uma pedagogia crítica, é o de trabalhar no sentido de ir além dos métodos e das técnicas, procurando associar escola-sociedade, teoria-prática, conteúdo-forma, técnica-política, ensino-pesquisa, ensino-avaliação, professor-aluno.

Portanto, buscou-se construir uma Didática crítica, pautada em uma "visão contextualizada e multidimensional do processo pedagógico" (CANDAU, 2011, p. 154), apoiada em Brasil (1998, 2002a), Candau (1983, 1996, 2011), Freire (1996), Libâneo (1986), Karnal (2003), D’ambrósio (1996), Veiga (2005), dentre outros. Nos excertos abaixo, é possível identificar quais foram os pressupostos teóricos significativos aos acadêmicos, no âmbito da disciplina ministrada:

A3: O que mais gostei na disciplina foi a leitura e discussão do livro Pedagogia da Autonomia, de Paulo Freire, pois lá encontrei respostas para enfrentar problemas da educação, desde desvalorização da profissão à falta de interesse dos alunos. Freire nos mostrou o quanto é importante conhecer o contexto para planejarmos o uso pedagógico de tecnologias para auxiliar na didática do professor, visando a construção de uma escola mais crítica, democrática e justa.

A5: A disciplina nos deu uma visão integrada e crítica da sala de aula, principalmente pela discussão dos textos sobre as concepções de educação presentes nas tendências pedagógicas, o 
papel do professor transformador da educação em Paulo Freire e a visão da didática, que vai além da parte técnica com Vera Candau. Os textos do PCN e do livro de Leandro Karnal foram fundamentais para quem quer ser professor de História. Ficou claro que a didática não é só maneira de ensinar, que tempos que refletir sempre nas questões políticas envolvidas no contexto da escola em que estivermos trabalhando.

Os sujeitos da pesquisa revelaram o processo de pensar a "própria prática pedagógica a fim de torná-la mais coerente com a realidade sociocultural" (VEIGA, 2005, p. 42), considerando que a Didática está relacionada com a emancipação humana; democratização da escola pública; apropriação crítica das TDIC e formação continuada de professores.

\section{Articulação do pensar sobre a Didática e a Didática "vivida"}

Candau (1983) destaca que a perspectiva fundamental da Didática "procura partir da análise da prática pedagógica concreta e seus determinantes" (p. 21), ou seja, tanto na formação inicial como na continuada, é necessário articular a teoria com a prática, "inclusive, reconstruir a própria teoria a partir da prática" (p. 111). Os trechos a seguir revelaram que os sujeitos da pesquisa reconheceram a importância de pensar e repensar o cotidiano escolar para a construção de consciência crítica e o redimensionamento da Didática.

A2: A disciplina nos ajudou a refletir sobre o contexto escolar, da sala de aula e seus desafios. A disciplina nos ensinou a escutar o que os alunos têm a dizer, dar valor as suas colaborações, ensinar com amor e com atitudes que favoreçam a mudança deles, ensinar não apenas conteúdo, mas a viver e mostrar sua importância, pois tornando-os amigos teremos mais facilidade para ensiná-los.

A5: A leitura do livro de Paulo Freire também abriu meus olhos sobre a nossa postura como educadores em relação aos desafios da educação, principalmente quando ele fala que ensinar exige esperança e alegria! Ele deixou claro que a educação é capaz de mudar a sociedade e de que nada adianta encher a lousa de conteúdos distantes da realidade dos alunos. Temos que respeitar as vivências deles e fazer com que eles consigam ir além do que já sabem.

O fato de repensar o cotidiano escolar, envolve, segundo Candau (1996), um trabalho conjunto entre os professores de Didática e os professores do ensino fundamental e médio, pois"somente nesta interação e troca de conhecimento que se produzirá um novo saber e fazer didáticos" (p. 18), também reconhecido pela avaliação dos sujeitos da pesquisa, nos seguintes excertos:

\begin{abstract}
A1 Na minha opinião, para a disciplina ser completa, faltou uma visita em uma escola do Estado, para discutir com os professores sobre as aulas de História.
\end{abstract}

A3: O que eu gostaria de acrescentar de contribuição seria talvez uma aula prática em uma escola, se fosse possível, para interagirmos com professores regentes de História. Visitamos a Escola Familiar Agrícola - EFA, que foi uma experiência muito legal, mas foi muito rápida, e não deu para conversar com os professores.

A9: A visita na EFA foi muito importante, mas deveria ter tido outras para conhecermos outras escolas e a experiência de outros professores.

Para superar a visão instrumental da Didática (CANDAU, 1996), concebendo o processo de ensino como "prática social concreta" (VEIGA, 2005), é importante articular a Didática vivida e o discurso sobre o que deveria ser esta própria prática. Durante esta investigação, buscou-se fazer tal articulação, avaliada pelos estudantes nos comentários:

A20: Para mim os conteúdos que vimos, as aulas que foram trabalhadas no laboratório de informática foi de fundamental importância para minha formação.

A1: A disciplina permitiu a aprendizagem ativa de nós acadêmicos, articulando a teoria e a prática. Vimos na prática estratégias didáticas como a importância de escrever na lousa a pauta da aula, o painel integrado como forma de trabalhar textos em grupos, o uso do prezi 
para elaboração de apresentações e a potencialidade do blog para a criação e divulgação de conteúdos. A meu ver, o uso das tecnologias contribuiu muito para a minha formação. Com o contato com aparatos tecnológico, que não tinha nem ideia que existissem, percebi que existem muitas formas de se trabalhar História, sem ser apenas por meio de aulas expositivas.

A7: Sem dúvida os métodos para envolver os alunos no processo de aprendizagem vividos na disciplina irão contribuir muito para enfrentarmos as dificuldades da escola. Aulas expositivas e dialogadas, vídeos e uso do computador para ultrapassar as paredes da sala de aula, foram inspiradoras e mostraram como articular a teoria com a prática. Compreender os alunos, conhecê-los, são requisitos fundamentais para uma boa relação professor-aluno. Tudo que aprendi e usarei nas minhas aulas com o objetivo de transformar o ensino de História e contribuir com a formação política, social e cidadã dos alunos.

Os sujeitos da pesquisa reconheceram a importância das tecnologias e seu papel formativo, articulado ao 'pensar' sobre a Didática com a Didática'vivida' no dia-a-dia da prática educativa. Conforme destaca Fantin (2012, p. 443):

é importante ir além da idéia de considerar o vídeo, a televisão, os filmes, o computador, a Internet, o celular, o mp3 e os tablets apenas como recursos ou aspectos importantes da educação ou como experiências audiovisuais que encorajam as pessoas a falarem sobre elas ajudando-as a serem leitoras e escritoras. Este argumento é válido, mas seu valor é limitado porque é sustentado em uma idéia de educação que se restringe à capacidade de ler e escrever. Para ir além, há que pensar o currículo como um repertório de saberes e competências correlacionadas e integradas a todas as mídias problematizando tanto a ênfase na leitura crítica e produção criativa como outras formas de consumoe práticas culturais.

Nesta pesquisa-ação, conforme Barbier (2002), a teoria decorreu da avaliação permanente da ação pedagógica desenvolvida pelas professoras-pesquisadoras envolvidas. Ao sistematizar e divulgar os resultados desta investigação, exercita-se a ação de refletir sobre as práticas de ensino e de aprendizagem cotidianas. Ao teorizar sobre elas e avaliá-las, "leva o resultado da pesquisa a um estabelecimento de modelos dos processos coletivos conduzindo à realização dos objetivos da ação, quer dizer, à resolução do problema inicial" (BARBIER, 2002, p. 144).

Portanto, conclui-se que os espaços nas licenciaturas para discussão dos sentidos formativos e didáticos das TDIC podem contribuir para evitar posições de supervalorização ou rejeição dos recursos digitais, evidenciando seu caráter como produções histórico-sociais. Entre os saberes e fazeres docentes já faz parte o processo de apropriação crítica das TDIC, reconhecendo suas potencialidades para o desenvolvimento do protagonismo docente e discente em suas produções e coautorias de conteúdos curriculares.

\section{Considerações Finais}

A proposta de revisão e reconstrução do ensino de Didática, problematizado por tecnologias digitais, partiu de uma parceria profícua entre duas professoras de cursos diferentes (História e Matemática), que motivou a importância de se pensar na operacionalização de uma pesquisa em prol da formação pedagógica de futuros professores de áreas disciplinares específicas.

Quanto à metodologia da pesquisa-ação desenvolvida no contexto da disciplina, foram seguidas etapas flexíveis. Constantemente, o planejamento das aulas foi submetido aos estudantes envolvidos que puderam manifestar suas observações, valores, sugestões e críticas, em busca de atender suas demandas de formação. A opção por essa modalidade de pesquisa buscou associar a investigação aos envolvidos, no sentido de contribuir para repensar o ensino de Didática.

As pesquisadoras, autoras da prática e do discurso, inseridas no processo e na ação pedagógica se envolveram na pesquisa, resultando numa mudança de atitudes, ao analisarem o desenvolvimento da disciplina e refletirem sobre novas perspectivas de ensino da Didática. 
A avaliação da proposta foi realizada pelos próprios acadêmicos, que reconheceram a especificidade dos conteúdos da Didática, voltada para a compreensão de que o professor deve buscar formas de intervenção na sala de aula, apoiadas na intencionalidade pedagógica do uso de TDIC no processo e ensino e de aprendizagem. A superação da Didática instrumental deve ser acompanhada da ideia de que a expressão "eficiência" do professor é incontestável. Em outras palavras, o professor deve sim estudar e pesquisar diferentes técnicas de ensino para colocar em prática, com competência, o ensino de conteúdos específicos articulados com questões sociais e políticas.

O processo de reconstrução do conteúdo da Didática foi identificado pelos acadêmicos no estudo dos fundamentos da ação docente, a partir de referenciais que possibilitaram uma visão contextualizada e multidimensional da prática educativa. Ao mesmo tempo, os acadêmicos também apresentaram suas críticas em relação ao desenvolvimento da disciplina, que serão objeto de reflexão no planejamento das próximas edições da disciplina.

Sobre o conteúdo da Didática, ficou evidente, para os sujeitos da pesquisa, que cada tendência pedagógica, os PCN e a visão dos autores trabalhados apresentaram fundamentos que podem orientar teoricamente a prática do professor. Por isso, a importância do professor ter clareza da sua concepção de educação, de homem, de sociedade, bem como investigar os pressupostos que possam iluminar e avaliar sua ação docente, aprimorando-a constantemente, diante dos diferentes desafios que se apresentam no cotidiano escolar.

Na articulação do pensar sobre a Didática e a Didática"vivida", os acadêmicos reconheceram na disciplina espaços para discussão de como lutar para operacionalizar mudanças na educação, pautadas na valorização do professor; em condições adequadas para o desenvolvimento da ação docente; na formação apoiada por conhecimentos e planejamentos metodológicos para o uso pedagógico de TDIC; no processo de problematizar o ensino e a aprendizagem; na gestão democrática escolar, na qual promova espaços para a colaboração e trocas de experiências docentes.
Portanto, pela avaliação dos sujeitos da pesquisa, existe aceitação da inovação nas metodologias de ensino, aliada à consciência política do professor, em busca de uma educação problematizadora. Os acadêmicos defenderam o uso de recursos tecnológicos na prática pedagógica no ensino fundamental e médio, desde que o professor tenha discernimento do sentido formativo das TDIC e que exista infraestrutura necessária para operacionalizar as inovações, com êxito, na educação básica, ou seja, houve reconhecimento da importância da mídia-educação como tema transversal na formação dos professores.

Nesse sentido, os cursos de licenciatura devem repensar a metodologia, em busca de práticas pedagógicas dinâmicas, provocadoras e desafiantes, que compreendam essa formação como um processo interminável de aprendizagem, apoiada por políticas públicas educacionais de desenvolvimento e de valorização profissional.

\section{Notas}

1 Prezi é um recurso da web 2.0 para a criação de apresentações não lineares, apoiadas no conceito de apresentações com zoom, integrando textos, links, imagens e vídeos.

2 Com o objetivo de preservar o anonimato e privacidade dos sujeitos desta pesquisa, cada acadêmico foi identificado com numeral de 1 a 21. Dessa forma, todos os excertos das falas foram identificados pela letra "A", de acadêmico, seguida do numeral correspondente ao sujeito.

\section{Referências}

BARBIER, René. A pesquisa-ação. Trad. Lucie Didio. Brasília: Plano Editora, 2002.

BRASIL. Ministério da Educação. Secretaria de Educação Básica. Parâmetros Curriculares Nacionais: História - $5^{\mathrm{a}}$ a $8^{\mathrm{a}}$ séries. Brasília: MEC/SEB, 1998.

Ministério da Educação. Secretaria de Educação Básica.

Parâmetros Curriculares Nacionais: Matemática - $5^{\text {a }}$ a $8^{\text {a }}$ séries. Brasília: MEC/SEB, 1998.

Ministério da Educação, Secretaria de Educação Média e Tecnológica. PCN+ Ensino Médio: orientações educacionais complementares aos Parâmetros Curriculares Nacionais. Ciências Humanas e suas Tecnologias. Brasília: MEC, SEMTEC, 2002a. - Conselho Nacional de Educação. Resolução CNE/CP 1/2002 de 18 de fevereiro de 2002. Institui Diretrizes Curriculares Nacionais para a Formação de Professores da Educação 
Básica, em nível superior, curso de licenciatura, de graduação plena. Diário Oficial da União, Brasília, 09 abr. 2002b.

CANDAU, Vera Maria. A didática em questão. 6.ed. Petrópolis: Vozes, 1983.

. (Org.). A revisão da Didática. In: CANDAU, Vera Maria. Rumo a uma nova Didática. 8.ed. Petrópolis: Vozes, 1996.

. Da Didática Fundamental ao Fundamental da Didática. In: ANDRÉ, Marli; OLIVEIRA, Maria Rita. Alternativas no ensino de didática. 12.ed. Campinas-SP: Papirus, 2011.

D'AMBRÓSIO, Ubiratan. Educação matemática: da teoria à prática. São Paulo: Papirus, 1996.

FANTIN, Monica. Mídia-educação no ensino e o currículo como prática cultural. Currículo sem Fronteiras, v. 12, n. 2, p. 437452, maio/ago., 2012.

FREIRE, Paulo. Pedagogia da Autonomia: Saberes Necessários à Prática Educativa. 6.ed. Rio de Janeiro: Paz e Terra, 1996.

LIBÂNEO, José Carlos. Democratização da escola pública: a pedagogia crítico-social dos conteúdos. São Paulo: Loyola, 1986.

; PIMENTA, Selma Garrido. Formação dos profissionais da educação: visão crítica e perspectivas de mudança. In: PIMENTA, Selma Garrido (Org.) Pedagogia e pedagogos: caminhos e perspectivas. São Paulo: Cortez, 2002. pp. 11-57

MOREIRA, Antonio Flavio Barbosa; KRAMER, Sonia. Contemporaneidade, educação e tecnologia. Educ. Soc. [online]. v.28, n.100, p. 1037-1057, out. 2007. Disponível em: <http://www. scielo.br/pdf/es/v28n100/a1928100.pdf>. Acesso em 07 Mar. 2010.

OLIVEIRA, Maria Rita Neto Sales. A didática e seu objetivo de estudo. Disponível em: <http://educa.fcc.org.br/pdf/edur/n08/ n08a07.pdf>. Acesso em 15 jan. 2015.

VEIGA, Ilma Passos Alencastro (Coord.). Repensando a Didática. 22.ed. Campinas-SP: Papirus, 2005.

et al. A didática na formação docente: entre a inovação técnica e a edificante. In: III EDIPE - Encontro Estadual de Didática e Prática de Ensino - 2009. Disponível em: <http:// www.ceped.ueg.br/anais/Illedipe/pdfs/2_trabalhos/gt09_didatica_praticas_ensino_estagio/trab_gt09_a_didatica_na_formacao_docente.pdf >. Acesso em 17 fev. 2015.

Recebido em 05 de maio de 2015.

Aceito em 20 de agosto de 2015. 